\title{
Cost objects: How is your ED performing?
}

\author{
Verónica Fuentes-Cáceres ${ }^{1}$, Liliana Neriz ${ }^{1}$, Alicia Núñez-Mondaca ${ }^{1 *}$ (DD and Ricardo Mateo ${ }^{2}$
}

\begin{abstract}
Background: The aim of this study is to a propose a standardized methodology to identify a list of cost objects that can be used by any ED to compute costs considering that the resulting data must facilitate unit management by improving the information available for decision-making.

Methods: This study considers two stages, first, we analyzed the case-mix of two hospitals collecting their data to define and diagram their processes, activities and to obtain their cost objects, second, we used four additional hospitals to validate our initial findings.

Results: We recognized 59 cost objects. Hospitals may have all these cost objects or just a subset of them depending on the services they provide.

Conclusions: Among the main benefits of our cost objects definition are: the possibility of tracing the processes generated by the services delivered by EDs, the economic sense in its grouping, the chance of using any costing methodology, the flexibility with other classification systems such as DRGs and ICDs, and the opportunity of costing for both diseases and treatments. Furthermore, cost comparison among hospitals using our final 59 cost objects list is more accurate and based on comparable units. In different EDs, each cost object will be the result of a similar combination of activities performed. We also present the results of applying this cost objects list to a particular ED. A total of 53 out of 59 cost objects were identified for that particular unit within a calendar year.
\end{abstract}

Keywords: Costs and cost analysis, Emergency service, hospital, Cost allocation, Process assessment

\section{Background}

Emergency care expenditures are a growing problem both in Chile and worldwide. The level of emergency care spending in the United States is between 5 and 6\% of the total health expenditure, reaching $10 \%$ in some states [1]. However, it is still unclear how much it costs to deliver emergency care worldwide. The reason is twofold. Firstly, cost calculation of clinical processes of Emergency Departments (EDs) does not allow comparison between healthcare units or services. Secondly, no standardized categorization for grouping costs has been defined, i.e. cost objects. A cost object is anything for which a separate measurement of costs is desired [2]. In

\footnotetext{
*Correspondence: anunez@fen.uchile.cl

${ }^{1}$ School of affiliation: Department of Management Control and Information Systems, School of Economics and Business, Universidad de Chile, Zip code: 8330015, Diagonal Paraguay 257, office, 2004 Santiago, Chile

Full list of author information is available at the end of the article
}

health care, cost objects could be patients, products, projects, service contracts, and any other work unit [3].

\section{Cost objects}

Different published studies use various types of cost objects for EDs. For example, cost objects of an ED can be classified into three types based on the patient's status: Urgency; Emergency and Non-Emergency [4]. This definition addresses the classification of patients from a more macro perspective. Other key cost objects that have been used for allocation are: Diagnostic Related Groups (DRGs) [5] and case-mix by using the international classification of diseases (ICD) [6]. These two classifications do not provide complete information about ED services, since they were designed to facilitate billing considering ED charges according to the acuity level of the patient and the intensity of supplies and

(c) The Author(s). 2020 Open Access This article is licensed under a Creative Commons Attribution 4.0 International License, which permits use, sharing, adaptation, distribution and reproduction in any medium or format, as long as you give appropriate credit to the original author(s) and the source, provide a link to the Creative Commons licence, and indicate if changes were made. The images or other third party material in this article are included in the article's Creative Commons licence, unless indicated otherwise in a credit line to the material. If material is not included in the article's Creative Commons licence and your intended use is not permitted by statutory regulation or exceeds the permitted use, you will need to obtain permission directly from the copyright holder. To view a copy of this licence, visit http://creativecommons.org/licenses/by/4.0/. The Creative Commons Public Domain Dedication waiver (http://creativecommons.org/publicdomain/zero/1.0/) applies to the data made available in this article, unless otherwise stated in a credit line to the data. 
services provided, so most of the time EDs are seen as an intermediate service.

Other studies consider cost objects just for a subset of ED cases, such as: division costs for services to specific patients, for example hospitalized patients [7] and preselected diseases [8]. Another methodology to compute the costs of the clinical processes in EDs, uses homogeneous functional groups, which are defined based on similar consumption activities followed by an imputation to clinical processes [9]. However, the authors do not present the cost objects and suggest that each hospital should code their own diseases according to the ICD. Similarly, other authors define cost objects clustering as groups whose services similar demands for ED functions (i.e. ambulatory patient groups, physicians' current procedural terminology groups) [10].

Other studies use cost centers related to patients [11]. However, the study does not distinguish the different services and processes carried out by the ED. It can be observed that there is still no consensus on how to classify cost objects for EDs. In fact, the choice of cost objects is difficult given the variety of services provided, yet very important. In this study we consider that a correct definition of cost objects should aim to measure the costs of either treatments or diseases if needed, and trace the processes and services provided by the ED considering the whole set of processes and activities the ED perform not just a subset.

Cost objects have enormous financial importance because they are the foundations of health insurance billing, and thus are tied to health systems financing. The lack of standardization and homogeneity in defining cost objects make comparing among units/services difficult and sometimes even impossible. Therefore a common definition of cost objects is required, in other words the same vocabulary for recording, reporting and monitoring emergency health problems. Thus, this paper aims to create a standardized methodology to identify a list of cost objects for EDs that can be used as a starting point to collect feasible data for decision-making purposes and to provide global data for analysis such as tracing processes, computing costs and allowing comparisons among other ED hospitals. Additionally, in order to test the viability of implementing this list of cost objects with a costing methodology, in this particular case we use the activity-based costing $(\mathrm{ABC})$ method.

In the healthcare sector, there have been attempts to apply the ABC costing methodology since the 1990s due to the need to have more accurate and practical costing systems for a more effective cost control [12-14]. There are some experiences in EDs arguing that this methodology allows for a better imputation of costs, eases processes monitoring, allows inter and intra-hospital comparisons, provides more realistic information and adapts better to the clinical decision process based on protocols $[9,15]$. Also, another study computed the total cost of patient care in an ED using Time-Driven Activity-Based Costing (TDABC) [16].

The next section presents the methodology used to achieve these purposes.

\section{Methods}

In order to determine cost objects in EDs, this study considers two stages and a sample including a total of six hospitals. The first stage includes both on-site observations and interviews conducted in two different EDs. To ensure a more representative sample, the first hospital selected (hospital 1 in Table 1) is located in Santiago (the Chilean capital), while the second hospital selected is located in a smaller urban city (hospital 2 in Table 1). The observation and interviewing process lasted approximately 3 months in each ED, and as a result, diagrams using the Unified Modeling Language (UML) were constructed for each unit. The diagrams were then validated with personnel with at least 5 years of work experience at the unit. Subsequently, to elaborate a more comprehensive diagram that included the complexity of both cases observed so far, the diagrams were compared to each other considering the similarity and variability of the tasks required in each process and the resources needed to performed them. For example, Hospital 2 included an area in which the patient's status was monitored while they remained under observation, whereas Hospital 1 did not include such a space because length of stay within the ED was less than $24 \mathrm{~h}$. Hence, the pathway followed by a patient that ends up being hospitalized differs from Hospital 1 to Hospital 2.

The purpose of the second stage of this study was to validate the resources employed (direct and indirect costs), as well as the activities performed and services delivered (cost objects) for EDs. Using convenience sampling, four additional EDs were selected to further validate the diagram (hospitals 3 through 6 in Table 1). Table 1 shows some relevant descriptive information about the hospitals included in this study, as well as descriptive information on the healthcare professionals that were involved in the validation process.

It is important to note that Chile is an upper-middle income country located in South America. The Chilean health care system is a mixed system, which is publicly and privately financed. There is a single public insurance (FONASA) and several private health insurance companies (ISAPREs). Most of Chilean citizens (70\%) are covered by FONASA. Workers can choose to be covered either by FONASA or one of the ISAPREs operating in the country. There are no barriers in FONASA to access to emergency care and highly complex pathologies. FONASA is structured in 4 groups classified by income 
Table 1 Hospitals ED included in the sample

\begin{tabular}{|c|c|c|c|c|c|c|}
\hline Institution & Used in & Characteristic & Medical Providers & Number of beds & $\begin{array}{l}\text { Interviewee's } \\
\text { position }\end{array}$ & $\begin{array}{l}\text { Years of } \\
\text { Experience }\end{array}$ \\
\hline \multirow[t]{3}{*}{ Hospital 1} & \multirow[t]{3}{*}{ Stage 1} & \multirow{3}{*}{$\begin{array}{l}\text { High Complexity and Private } \\
\text { Teaching Hospital. }\end{array}$} & \multirow{3}{*}{$\begin{array}{l}\text { EM Specialists, Medical } \\
\text { interns, Residents }\end{array}$} & \multirow[t]{3}{*}{607} & Physician & 6 \\
\hline & & & & & Physician & 8 \\
\hline & & & & & Nurse & 10 \\
\hline \multirow[t]{2}{*}{ Hospital 2} & \multirow[t]{2}{*}{ Stage 1} & \multirow{2}{*}{$\begin{array}{l}\text { High Complexity and Public } \\
\text { Teaching Hospital. }\end{array}$} & \multirow{2}{*}{$\begin{array}{l}\text { EM Specialists, Medical } \\
\text { interns, Residents }\end{array}$} & \multirow[t]{2}{*}{466} & Nurse & 11 \\
\hline & & & & & Nurse & 8 \\
\hline \multirow[t]{3}{*}{ Hospital 3} & \multirow[t]{3}{*}{ Stage 2} & \multirow[t]{3}{*}{ High Complexity Public Hospital. } & \multirow[t]{3}{*}{ EM Specialists, Residents } & \multirow[t]{3}{*}{340} & Physician & 7 \\
\hline & & & & & Physician & 5 \\
\hline & & & & & Nurse & 18 \\
\hline \multirow[t]{3}{*}{ Hospital 4} & \multirow[t]{3}{*}{ Stage 2} & \multirow{3}{*}{$\begin{array}{l}\text { Specialty High Complexity Public } \\
\text { Hospital. }\end{array}$} & \multirow[t]{3}{*}{ EM Specialists, Residents } & \multirow[t]{3}{*}{176} & Physician & 12 \\
\hline & & & & & Nurse & 21 \\
\hline & & & & & Technician & 6 \\
\hline Hospital 5 & Stage 2 & High Complexity Public Hospital. & EM Specialists & 211 & Physician & 8 \\
\hline \multirow[t]{2}{*}{ Hospital 6} & \multirow[t]{2}{*}{ Stage 2} & \multirow[t]{2}{*}{ High Complexity Public Hospital. } & \multirow[t]{2}{*}{ EM Specialists, Residents } & \multirow[t]{2}{*}{545} & Physician & 8 \\
\hline & & & & & Physician & 8 \\
\hline
\end{tabular}

(A to D from lower to higher income). People in groups $A$ and $B$ receive free health care services, group $C$ have to pay $10 \%$ cost-sharing, and group D pay $20 \%$ of health services. In case of an emergency public beneficiaries will face the same copayments. Except for Group A, the rest have the option of using private health care facilities subscribed by FONASA. On the other hand, ISAPREs can offer different premiums to their customers to improve their health plans; most of their beneficiaries use private facilities [17]. There are copayments for people with private insurance when emergency services required exceed the plan's ability to pay. In case of lifethreatening situations, patients can receive medical attention from any ED.

In the following paragraphs we present a step by step description of the methodology executed to construct cost objects for EDs. Steps 1 through 5 correspond to stage 1 of this study, while step 6 and 7 correspond to stage 2 .

\section{Stage 1: identifying cost objects \\ Step 1: collecting the data to define processes}

Through observation and interviews with all healthcare professionals working at the two EDs included in this study at this point (hospital 1 and 2), all the processes performed within the ED were identified, considering all the tasks needed to carry them out. Each one of the tasks is considered an activity and a comprehensive list including all the activities identified (73) was elaborated. Observation occurred at different points in time (season, day of the week and time during the day) to account for seasonal effects.

\section{Step 2: diagraming the processes}

Using a workflow chart (using UML), all the activities identified in the previous step were diagramed considering which ones needed to be performed in sequence and which ones could be conducted in parallel. A process involves a series of activities to achieve a particular end, we identified a total of 6 processes out of 73 activities.

\section{Step 3: checking the databases available to complete the process information}

To make sure that all the processes needed to provide services that could be performed at the ED were considered, a list of all services accounted for each patient within the last 2 years was checked. When services provided very unfrequently were detected, the processes needed to provide them were included in the workflow charts, and therefore, the processes needed to perform them were identified.

\section{Step 4: elaborating and validating processes and activities performed by the ED}

All the tasks (activities) for each process were defined. The comprehensive list of activities identified, now all included in a workflow chart, were validated using the expertise of at least one physician and one nurse from the ED, preferably those that had being working at the department the longest (see Table 1). Validation of both the description and the succession of the activities occurred.

\section{Step 5: defining cost objects for the ED}

Once the list of identified activities was validated, groups of activities were created using three criteria. Firstly, 
activities were grouped according to their nature and sequence. The groups must be mutually exclusive in terms of activities, to avoid double counting when costing patients and represent $100 \%$ of the services provided by the ED. The latter translates into having combinations of groups of activities that are consumed by patients without having an overlap of activities performed, unless those activities are in actuality executed multiple times. Each one of the groups elaborated will become a cost object of the ED. Secondly, these cost objects will allow us to trace back the processes and services the ED perform. Thirdly, these cost objects can be aggregated in order to compute the costs of treatments and diseases (using any coding system). The final list of cost objects (59) corresponds to the services provided by the ED unit.

\section{Stage 2: validating the cost objects}

\section{Step 6: external validation of the activities}

The final list of activities from stage 1 was validated in four EDs by healthcare professionals with expertise at the unit (see hospital 3 to 6 in Table 1).

\section{Step 7: external validation of the cost objects}

The final list of cost objects from stage 1 was validated in the same four EDs by the same healthcare professionals as the previous step (see hospital 3 to 6 in Table 1).

After the validation process we tested the feasibility of applying these cost objects in order to calculate costs using the $\mathrm{ABC}$ method at a particular ED. We chose the $\mathrm{ABC}$ methodology because it has being posed as a promising model for measuring costs and for making effective cost improvement decisions for the ED. We followed Kaplan \& Cooper approach [18] by:

1. Developing the activity dictionary.

2. Determining how much the ED is spending on each of its activities.

3. Identifying the ED's products, services and patients, i.e. our cost objects list.

4. Selecting activity cost drivers that link activity costs to the ED's products, services and patients.

The list of cost objects and activities derived from this study as well as the application of the ABC method are presented in the results section.

\section{Results}

As shown in Table 2, we identified a total of 59 cost objects for EDs. A particular ED may provide all the services listed in Table 2 or a subset of them.

Below we present the costs for all the cost objects identified in the ED from Hospital 1, using the $A B C$ method. As shown in Table 1, Hospital 1 is a high complexity and private teaching hospital with more than six hundred beds. As a teaching hospital, patients can be treated by EM specialists, medical interns and residents. The ER at this hospital has a medical and trauma unit, as well as a critical care unit, with 10 boxes in total. The layout of this ER also includes a triage area.

We calculated the cost of 53 out of the 59 cost objects that this ED provided within a calendar year. We identified and cost 6 processes and 73 activities. Figure 1 shows the indirect costs of the processes that took place in the selected ED.

As shown in Fig. 1, the medical care process has the higher proportion $(36.9 \%)$ of indirect costs whereas the administrative and logistic processes consume more than half $(52.1 \%)$ of the indirect resources. The indirect resources included in this $\mathrm{ABC}$ application can be categorized as: salaries, depreciation of equipment and infrastructure, utilities and medical supplies, office supplies, and maintenance. In order to carry out $A B C$, we need to recognize the tasks that make up these processes, i.e. the activities. To assign indirect resources to the activities, we define resource drivers such as time, number of procedures, number of employees/ time, usage percentage, and square meters/time.

Once activity costs were calculated, then activities were assigned to the cost objects. To allocate the cost of the activities we use the following cost drivers: time, number of procedures, and consumption index. Table 3 presents the eight most expensive activities from this ED.

According to Table 3, the most expensive activities are medical evaluation $(\$ 146,054,786$ chilean pesos, equivalent to US\$225,000) and re-evaluation $(\$ 152,047,070$ chilean pesos, equivalent to US $\$ 234,000$ ). The main reasons for the elevated costs of these activities are the physicians' salaries and equipment and infrastructure costs.

The next step of $\mathrm{ABC}$ is to allocate the cost of the activities to the cost objects. The cost objects are the 53 services provided by the ED. Table 4 shows the final allocation of direct and indirect costs to these services. The services with the highest total costs are medical consultation $(\$ 487,445,524$ chilean pesos, equivalent to US $\$ 750,000)$, phleboclysis $(\$ 97,601,148$ chilean pesos, equivalent to US\$150,000) and preparation of patients for hospitalization $(\$ 93,013,711$ chilean pesos, equivalent to US\$143,000). Eighty percent of the medical consultation costs come from three activities: medical evaluation, re-evaluation and filling health records for patients. Similarly, $80 \%$ of the phleboclysis services' cost relates to four activities: intravenous (IV) installation, withdraws of supplies for procedures, medication administration and sample taking activities, registering medical supply consumption, and storage control. For preparation of patients for hospitalization the highest costs $(78 \%)$ are associated with three activities: filling nursing 
Table 2 List of Cost Objects for EDs

\begin{tabular}{ll}
$\mathbf{N}^{\circ}$ & Services \\
\hline $1 \quad \begin{array}{l}\text { Administration of drugs by subcutaneous } \\
\text { or intravenous injection }\end{array}$
\end{tabular}

2 Administration of non-injectable drugs

3 Administration of non-injectable prescribed drugs

4 Administration of prescribed drugs by subcutaneous or intravenous injection

5 Alcohol screening test

6 Application of a larger orthopedic medical cast

7 Application of a shorter orthopedic medical Procedure in which a short orthopedic cast is used to treat a trauma condition. cast

8 Arterial blood gas sample

9 Black braided silk suture

10 Bladder instillation

11 Blood culture sample

12 Blood glucose test

13 Blood sampling

14 Burn wound dressing

15 Catgut suture

16 Complex foreign body extraction

17 Complex wound dressing

18 Diagnostic and therapeutic puncture

19 Diagnostic puncture

20 Discharge of deceased patients

21 Electrocardiogram

\section{$\mathbf{N}^{\circ}$ Services}

22 Endotracheal intubation

23 Enema

24 Feeding tube insertion

25 Histoacryl

26 Intramuscular drugs administration

\section{Description}

Administration of injectable medications of medications that can be administered to the patient without an additional approval process or paperwork because they are not controlled drugs.

Administration either oral, buccal or other enteral route for non-injectable medications

of medications that can be administered to the patient without an additional approval process or paperwork because they are not controlled drugs.

Administration either oral, buccal or other enteral route for prescribed non-injectable medication of medications that cannot be administered to the patient without an additional approval process or paperwork because they are controlled drugs.

Administration of injectable medications of medications that cannot be administered to the patient without an additional approval process or paperwork because they are controlled drugs.

Application of validated screening tools for alcohol misuse and alcohol use disorder.

Procedure in which a large orthopedic cast is used to treat a trauma condition.

Arterial blood gas (ABG) sampling to obtain information on a patient's respiratory status (blood oxygen and carbon dioxide levels), as well as the patient's acid-base balance.

Procedure for approximation and/or litigation of soft tissue in which a black braided silk suture is used. This type of surgical suture is a non-absorbable multifilament composed of an organic protein.

Bladder instillation is a combination drug therapy to help painful bladder or cystitis type symptoms including frequency, urgency, burning pain or stinging sensations when passing urine. It works by reducing inflammation and discomfort within the bladder.

Blood culture collection to test for foreign invaders like bacteria, yeast, and other microorganisms in the blood.

Procedure to test the amount of glucose in blood.

Blood specimen collection to obtain blood for laboratory testing.

Procedure to dress a dermal burn to absorb fluid, avoid maceration and seal the wound from the outside environment to reduce pain and infection.

Surgical suture procedure in which a catgut suture is used. This type of suture is naturally degraded by the body's own proteolytic enzymes. It is used for surgical procedures such as general closure, ophthalmic and orthopedics.

Complex localization, incision and removal of foreign bodies because of the location of the foreign body inside the patient's body and the material or shape of the foreign body.

Procedure to dress a complex wound that requires specialist wound care intervention. Complex wound dressing often is a result of the treatment of any number of other conditions, including cardiac, pulmonary, neuromuscular and renal diseases.

Medical diagnostic and therapeutic puncture for sample and treatment purposes.

Medical diagnostic puncture for sample purposes.

It involves all the administrative processes the ED needs to follow to discharge deceased patients.

Test provided at the ED to evaluate whether the patient's heart is beating at a normal rate and strength.

\section{Description}

Endotracheal intubation is a medical procedure in which a tube is placed into the trachea, usually through the mouth, to assist breathing.

Procedure used to stimulate stool evacuation.

Technique in which a nasogastric tube is inserted into the patient's nose, reaching first the back of the throat and then pushed down the esophagus until it reaches the stomach.

Procedure in which histoacryl is applied for closing skin wounds.

Technique used to deliver medications deep into the muscles through an injection of medications that can be administered to the patient without an additional approval process or paperwork because they are not controlled drugs. 
Table 2 List of Cost Objects for EDs (Continued)

\begin{tabular}{l}
$\mathbf{N}^{\circ}$ Services \\
\hline $27 \begin{array}{l}\text { Intramuscular prescribed drugs } \\
\text { administration }\end{array}$ \\
28 Installation of a removable cast walker boot \\
29 IV fluid change \\
30 Life risk care management \\
31 Management of imaging tests \\
32 Medical attention of patients arrived by \\
33 Medical consultation
\end{tabular}

34 Medical interconsultation

35 Medium-complex foreign body extraction

36 Monofilament nylon suture

37 Nebulization

38 Observation day

39 Orthopedic trauma medical attention

40 Oxygen therapy

41 Phleboclysis

42 Polypropylene suture

43 Preparation of patients for hospitalization

44 Preparation of patients for surgery

45 Reduction

46 Referral

47 Resuscitation

48 Secretion clearance

49 Simple foreign body extraction

50 Simple wound dressing

51 Skin suture

52 Splinting

53 Stomach pumping

\section{Description}

Technique used to deliver medications deep into the muscles through an injection of medications that cannot be administered to the patient without an additional approval process or paperwork because they are controlled drugs.

Procedure in which a removable cast walker boot is placed to treat trauma conditions such as severe sprains, fractures, and tendon or ligament tears in the ankle or foot.

Procedure in which the IV fluid bag is change for another one based on the needs of the patient. It involves all the administrative processes the ED needs to follow to admit a patient with a lifethreatening condition regardless of their ability to pay.

It involves all the administrative processes the ED needs to follow to ensure that an ED patient is scheduled (if an appointment is required) for the imaging tests prescribed and transported from the ED to the Imaging Unit and back to the ED.

It involves all the administrative processes the ED needs to follow to admit a patient arriving by ambulance.

It includes the administrative process required to admit the patient into the ED, as well as the physician's evaluation.

It includes the administrative process required to ask a specialist to further evaluate the patient, in order to correctly diagnose the patient, as well as the specialist's evaluation.

Medium-complex localization, incision and removal of foreign bodies because of the location of the foreign body inside the patient's body or the material or shape of the foreign body.

Procedure for approximation and/or litigation of tissue in which a monofilament nylon suture is used. This type of suture is non-absorbable by the body.

Procedure in which a nebulizer is used to treat a person with asthma or another respiratory condition to administer medication directly and quickly to the lungs.

It involves all the procedures required to monitor the patient's status while the patient remains under observation.

It includes the administrative process required to admit the patient into the ED, as well as the evaluation of the patient's condition by an orthopedic trauma specialist.

Procedure in which oxygen is provided if oxygen saturation on a patient is below the threshold defined as desirable for the patient's condition in order to reach the targeted oxygen saturation level.

It corresponds to the administration of fluids intravenously drop by drop, by the drip method, through a peripheral catheter.

Procedure for approximation and/or litigation of tissue in which a polypropylene suture is used. This type of suture is non-absorbable by the body.

It includes the administrative process, preparation and transference of patients to be hospitalized.

It includes the administrative process, preparation and transference of patients for surgery.

Procedure to repair a fracture or dislocation to the correct alignment without surgery.

It includes all the administrative processes required to transfer a patient to another hospital, primarily because the hospital currently treating the patient has not all the resources required to successfully treat the patient's condition.

A life-saving procedure performed when someone has stopped breathing or the heart has stopped beating, as in cardiopulmonary resuscitation (CPR).

Technique aiming to remove sputum (the combination of mucus and saliva) from the patient's lungs.

Simple localization, incision and removal of foreign bodies because the foreign body is located in a place of the body easy to reach and the material or shape of the foreign body are not likely to cause harm while the extraction process is conducted.

Procedure to dress a simple wound. This type of wound is defined as a dry dressing, apply to viable skin which does not require specialist wound care intervention.

Procedure for approximation and/or litigation of tissue using cutaneous suture.

Procedure to apply a rigid or flexible device that maintains in position a displaced or movable part; also used to keep in place and protect an injured part.

Procedure of cleaning out the contents of the stomach through a gastric lavage. 
Table 2 List of Cost Objects for EDs (Continued)

\begin{tabular}{lll}
\hline $\mathbf{N}^{\circ}$ Services & Description \\
\hline 54 & Stool sample & Stool specimen collection to obtain stool (feces) for laboratory testing. \\
55 Teaching activities & It includes all the teaching and research activities carried out within the ED. \\
56 Urethral sounding & $\begin{array}{l}\text { Procedure that involves inserting a sound into the urethra for dilatation of strictures or for } \\
\text { obtaining access to the bladder. }\end{array}$ \\
57 Urine specimen collection & Urine specimen collection to obtain urine for laboratory testing. \\
58 Verify injuries & Procedures requested by a judicial order or the police to verify type and severity of injuries. \\
59 Vicryl suture & Procedure for approximation and/or litigation of tissue using vicryl suture. This type of suture is \\
& absorbable, synthetic, and normally braided.
\end{tabular}

and medical records for hospitalization activities, and preparing patients for transporting. However, if the unit cost is considered, the most expensive services correspond to referral $(\$ 134,507$ chilean pesos, equivalent to US\$207), resuscitation ( $\$ 131,859$ chilean pesos, equivalent to US\$203), and diagnostic and therapeutic puncture (\$ 43,526 chilean pesos, equivalent to US\$67).

The proposed cost objects list can also be used to accumulate costs at different levels, such as patient or diagnoses. Table 5 shows an example of how the costs objects proposed can be aggregated at a diagnosis level, using the Pneumonia due to Streptococcus pneumoniae diagnosis (code J13 in the ICD-10 coding system).

As shown in Table 5, treating a patient diagnosed with Pneumonia due to Streptococcus pneumoniae costs $\$ 43$, 710 chilean pesos. This cost includes only the services provided by the ED. However, the revenue linked to those services could be imputed to the ED or to another unit at the hospital, given the classification of the services for billing purposes. In this particular case, the total revenue imputed to the ED corresponded to $\$ 19$, 050 chilean pesos. Hence, the ED had losses for an average of $\$ 24,660$ chilean pesos per patient treated for that diagnosis in the time period included in the analysis.

The results are discussed in the next section.

\section{Discussion}

This study proposes a methodology to identify a cost objects list for EDs that facilitates their management by improving the information available for decision-making. The analyzed case-mix allowed us to recognize 59 cost objects. This list of cost objects is better than the proposals to date because it meets with the following three design criteria: 1) Cost Objects are related to diseases, their treatments and their associated activity groups; 2 ) they are mutually exclusive and represent $100 \%$ of the services; 3 ) It allows us to trace back the processes and services provided by the ED. Hospitals may have all these cost objects or just a subset of them depending on the services they provide. The method proposed in this study can be applied to any hospital; however the final list of cost objects may differ depending on the treated cases. Moreover, the final list may end up with new cost

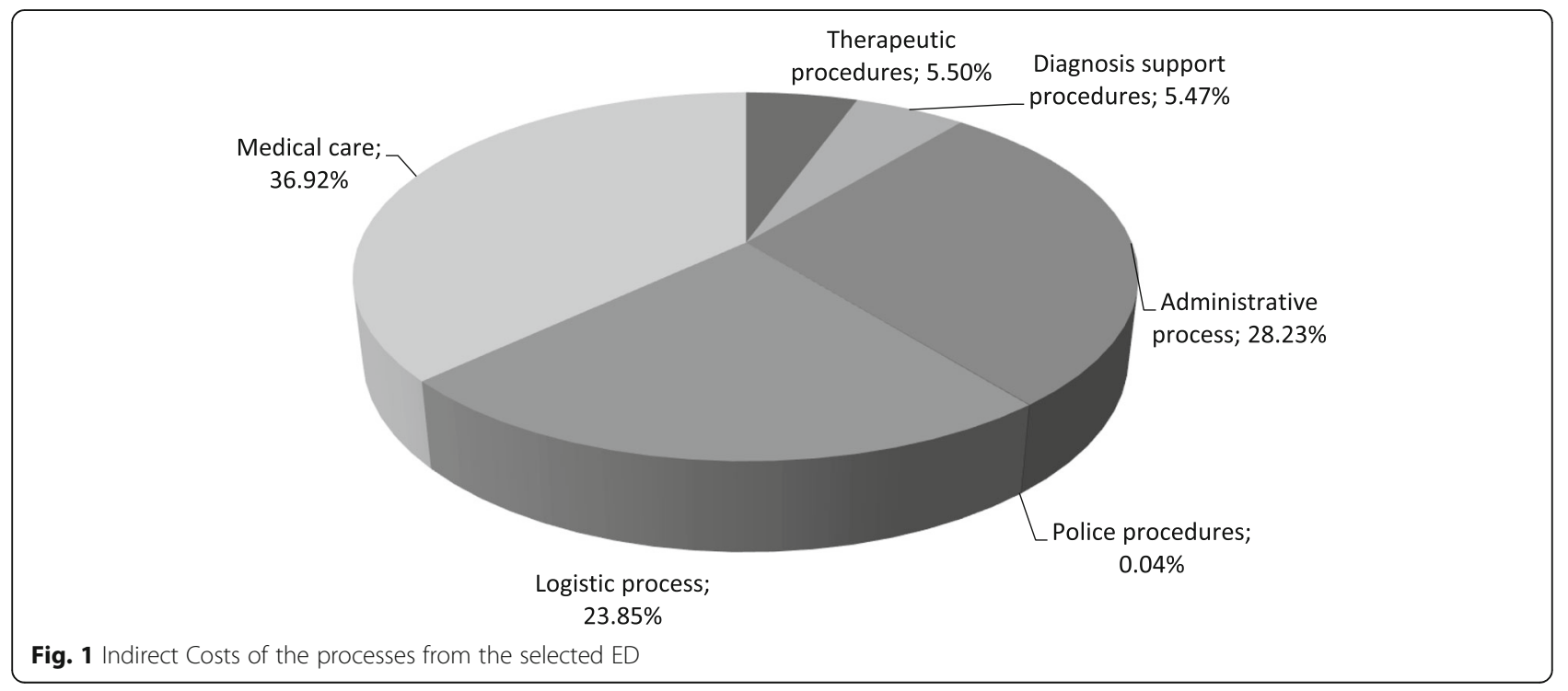


Table 3 Eight most expensive activities (Chilean Pesos $=$ CLP)

\begin{tabular}{llll}
\hline Ranking & Activity name & Process name & Annual Cost (CLP) \\
\hline 1 & Medical re-evaluation & Medical care & $\$ 152,047,070$ \\
2 & Medical evaluation & Medical care & $\$ 146,054,786$ \\
3 & Record indications to the patient & Administrative process & $\$ 88,170,350$ \\
4 & Patient management for imaging examination & Logistic process & $\$ 54,408,062$ \\
5 & Management of the unit & Administrative process & $\$ 37,020,211$ \\
6 & Clinical admission & Administrative process & $\$ 36,199,886$ \\
7 & Withdraw supplies for procedures, meds administration and sample taking & Logistic process & $\$ 34,493,631$ \\
8 & Take vital signs & Diagnosis support procedures & $\$ 29,179,405$ \\
\hline
\end{tabular}

objects based on differences in practices across countries.

Both the method to define cost objects for EDs and the cost objects list proposed are independent of the costing methodology employed. For instance, either activity-based costing or volume-based costing may be used to calculate costs. Our methodology is flexible because it recognizes activities that are aggregated according to a defined criterion to identify the final cost object list of services provided by any ED. In terms of information systems, using volume-based costing all that is required are the aggregated costs of the ED for the period under analysis, and then the selection of one driver to allocate the ED's resources to compute the cost of the cost objects list. On the other hand, the ABC methodology used in this study allows us to aggregate the costs of activities or cost objects providing detailed information for the ED. For example, aggregating activities or cost objects at the condition level, the patient level, etc.

In comparison with previous studies, such as those using patient's severity status as cost objects (Urgency; Emergency and Non-Emergency) [4], our proposed cost objects may both reach this level of aggregation as well as others, such as diagnoses, pre-selected diseases, casemix and services. The same advantage can be seen when comparing to the cost objects proposal by several other authors $[5,7,8]$. Among the main benefits of our cost objects definition are: the possibility of tracing the processes generated by the services delivered by EDs, the economic sense in its grouping, the chance of using any costing methodology, the flexibility with other classification systems such as DRGs and ICDs, and the opportunity of costing for both diseases and treatments. Furthermore, cost comparison among hospitals using our final 59 cost objects list is more accurate and based on comparable units. In different EDs, each cost object will be the result of a similar combination of activities performed.

The definition of cost objects is crucial, because hospital managers can expand their analysis by focusing on continuous improvement to increase the value of care.
The complexity of EDs provide a valuable setting to apply $\mathrm{ABC}$ given the high activity variability and hard predictability of demand. Additionally, calculating costs through $\mathrm{ABC}$ would help focus improvement efforts even more, for example, it would help detect which activities do not add value, optimize processes of providing services and provide more realistic cost estimates to make better managerial or strategic decisions [19].

The use of the proposed methodology makes it possible to associate cost objects with service revenue. This enables assessing the margin by each group of services. In addition, it facilitates the creation of transfer prices between different units of a hospital. In the case of the emergency unit this is especially important because many of the patients are transferred to or attended by other units. In these cases the ED does not receive the proportional compensation corresponding to the services delivered, such as, management of imaging tests, preparation of patients for surgery and medical interconsultation. Therefore, this methodology could help assess the potential economic impact of an ED within the hospital.

This study has limitations due to (1) differences in practices across institutions and countries, as well as changes in practices over time due to the development of new knowledge; and (2) sample size used for validation purposes. Even though the proposed methodology for defining cost objects is applicable to any case, the list of cost objects generated as a result of this study may not include all the services that could be provided in an ED for three reasons. First, this study analyzed a sample of six EDs. Second, technological advances could change services currently provided and make others obsolete. Lastly, epidemiological changes may demand new services.

The systematic application of this cost objects definition will enable managers to have better cost information for analysis and decision-making to avoid underfunding of EDs. Additionally, calculating these cost objects over time will allow internal comparability and benchmarking with other ED facilities. If we observed 
Table 4 Total Costs for ED Cost Objects (Chilean Pesos = CLP) including direct and indirect costs

\begin{tabular}{|c|c|c|c|c|c|}
\hline Ranking & Services & Indirect Costs & Direct Costs & Total Costs & Unit Costs \\
\hline 1 & Medical consultation & $\$ 487,445,524$ & & $\$ 487,445,524$ & $\$ 11,710$ \\
\hline 2 & Phleboclysis & $\$ 67,044,073$ & $\$ 30,557,075$ & $\$ 97,601,148$ & $\$ 7426$ \\
\hline 3 & Preparation of patients for hospitalization & $\$ 91,101,584$ & $\$ 1,912,126$ & $\$ 93,013,711$ & $\$ 17,007$ \\
\hline 4 & Management of imaging tests & $\$ 71,325,226$ & & $\$ 71,325,226$ & $\$ 5689$ \\
\hline 5 & Resuscitation & $\$ 37,052,388$ & & $\$ 37,052,388$ & $\$ 131,859$ \\
\hline 6 & Blood sampling & $\$ 30,124,604$ & $\$ 392,805$ & $\$ 30,517,409$ & $\$ 5795$ \\
\hline 7 & Urine specimen collection & $\$ 18,900,132$ & $\$ 56,725$ & $\$ 18,956,857$ & $\$ 4180$ \\
\hline 8 & Electrocardiogram & $\$ 10,555,702$ & $\$ 150,097$ & $\$ 10,705,798$ & $\$ 4603$ \\
\hline 9 & Preparation of patients for surgery & $\$ 8,932,030$ & $\$ 438,436$ & $\$ 9,370,466$ & $\$ 7472$ \\
\hline 10 & Life risk care management & $\$ 9,080,651$ & & $\$ 9,080,651$ & $\$ 9053$ \\
\hline 11 & Referral & $\$ 7,801,401$ & & $\$ 7,801,401$ & $\$ 134,507$ \\
\hline 12 & Administration of prescribed drugs by subcutaneous or intravenous injection & $\$ 7,655,239$ & $\$ 80,933$ & $\$ 7,736,172$ & $\$ 7130$ \\
\hline 13 & Administration of noninjectable prescribed drugs & $\$ 7,451,112$ & & $\$ 7,451,112$ & $\$ 5714$ \\
\hline 14 & Monofilament nylon suture & $\$ 6,892,450$ & $\$ 290,026$ & $\$ 7,182,476$ & $\$ 24,265$ \\
\hline 15 & Simple wound dressing & $\$ 6,744,059$ & $\$ 333,805$ & $\$ 7,077,865$ & $\$ 7327$ \\
\hline 16 & Complex wound dressing & $\$ 6,889,495$ & $\$ 122,572$ & $\$ 7,012,068$ & $\$ 23,530$ \\
\hline 17 & Administration of drugs by subcutaneous or intravenous injection & $\$ 6,201,138$ & $\$ 112,933$ & $\$ 6,314,072$ & $\$ 4170$ \\
\hline 18 & Teaching activities & $\$ 6,225,455$ & & $\$ 6,225,455$ & - \\
\hline 19 & Administration of noninjectable drugs & $\$ 5,515,973$ & & $\$ 5,515,973$ & $\$ 3032$ \\
\hline 20 & Nebulization & $\$ 4,330,711$ & $\$ 1,005,900$ & $\$ 5,336,612$ & $\$ 4202$ \\
\hline 21 & Arterial blood gas sample & $\$ 5,286,625$ & & $\$ 5,286,625$ & $\$ 3876$ \\
\hline 22 & Splinting & $\$ 2,187,641$ & $\$ 2,262,020$ & $\$ 4,449,661$ & $\$ 15,135$ \\
\hline 23 & Blood glucose test & $\$ 2,945,942$ & $\$ 147,546$ & $\$ 3,093,488$ & $\$ 4701$ \\
\hline 24 & Application of a shorter orthopedic medical cast & $\$ 1,904,884$ & $\$ 955,495$ & $\$ 2,860,379$ & $\$ 11,173$ \\
\hline 25 & Installation of a removable cast walker boot & $\$ 289,805$ & $\$ 2,509,500$ & $\$ 2,799,305$ & $\$ 26,660$ \\
\hline 26 & Orthopedic trauma medical attention & $\$ 2,348,362$ & & $\$ 2,348,362$ & $\$ 6452$ \\
\hline 27 & Black braded silk suture & $\$ 2,212,104$ & $\$ 80,069$ & $\$ 2,292,173$ & $\$ 24,128$ \\
\hline 28 & Intramuscular prescribed drugs administration & $\$ 1,848,525$ & $\$ 20,737$ & $\$ 1,869,262$ & $\$ 6724$ \\
\hline 29 & Medical interconsultation & $\$ 1,724,532$ & & $\$ 1,724,532$ & $\$ 1342$ \\
\hline 30 & Intramuscular drugs administration & $\$ 1,476,210$ & $\$ 28,942$ & $\$ 1,505,152$ & $\$ 3879$ \\
\hline 31 & Application of a larger orthopedic medical cast & $\$ 622,032$ & $\$ 855,619$ & $\$ 1,477,650$ & $\$ 24,628$ \\
\hline 32 & Stool sample & $\$ 1,461,081$ & $\$ 4253$ & $\$ 1,465,334$ & $\$ 4310$ \\
\hline 33 & Skin suture & $\$ 1,280,692$ & $\$ 29,963$ & $\$ 1,310,655$ & $\$ 23,830$ \\
\hline 34 & Stomach pumping & $\$ 983,161$ & $\$ 92,603$ & $\$ 1,075,764$ & $\$ 12,225$ \\
\hline 35 & Vicryl suture & $\$ 745,130$ & $\$ 35,083$ & $\$ 780,212$ & $\$ 24,382$ \\
\hline 36 & Histoacryl & $\$ 528,726$ & $\$ 10,882$ & $\$ 539,608$ & $\$ 12,549$ \\
\hline 37 & Endotracheal intubation & $\$ 478,748$ & $\$ 23,326$ & $\$ 502,074$ & $\$ 12,246$ \\
\hline 38 & Diagnostic puncture & $\$ 453,459$ & $\$ 21,398$ & $\$ 474,857$ & $\$ 29,679$ \\
\hline 39 & Diagnostic and therapeutic puncture & $\$ 390,482$ & $\$ 44,779$ & $\$ 435,261$ & $\$ 43,526$ \\
\hline 40 & Alcohol screening test & $\$ 375,863$ & & $\$ 375,863$ & $\$ 19,782$ \\
\hline 41 & Medical attention of patients arrived by ambulance & $\$ 254,133$ & & $\$ 254,133$ & $\$ 12,707$ \\
\hline 42 & Catgut suture & $\$ 209,568$ & $\$ 9610$ & $\$ 219,178$ & $\$ 24,353$ \\
\hline 43 & Blood culture sample & $\$ 207,715$ & $\$ 8157$ & $\$ 215,873$ & $\$ 6349$ \\
\hline 44 & Polypropylene suture & $\$ 186,282$ & $\$ 19,626$ & $\$ 205,909$ & $\$ 25,739$ \\
\hline
\end{tabular}


Table 4 Total Costs for ED Cost Objects (Chilean Pesos = CLP) including direct and indirect costs (Continued)

\begin{tabular}{|c|c|c|c|c|c|}
\hline Ranking & Services & Indirect Costs & Direct Costs & Total Costs & Unit Costs \\
\hline 45 & Discharge of deceased patients & $\$ 146,451$ & & $\$ 146,451$ & $\$ 9763$ \\
\hline 46 & Urethral sounding & $\$ 118,086$ & $\$ 12,822$ & $\$ 130,908$ & $\$ 32,727$ \\
\hline 47 & Complex foreign body extraction & $\$ 117,215$ & $\$ 590$ & $\$ 117,806$ & $\$ 16,829$ \\
\hline 48 & IV fluid change & $\$ 95,742$ & $\$ 5622$ & $\$ 101,364$ & $\$ 2981$ \\
\hline 49 & Reduction & $\$ 95,091$ & & $\$ 95,091$ & $\$ 5283$ \\
\hline 50 & Oxygen therapy & $\$ 36,802$ & $\$ 23,757$ & $\$ 60,558$ & $\$ 3785$ \\
\hline 51 & Verify injuries & $\$ 51,283$ & & $\$ 51,283$ & $\$ 4274$ \\
\hline 52 & Medium-complex foreign body extraction & $\$ 16,662$ & & $\$ 16,662$ & $\$ 16,662$ \\
\hline 53 & Simple foreign body extraction & $\$ 16,579$ & & $\$ 16,579$ & $\$ 16,579$ \\
\hline
\end{tabular}

that two hospitals have a different unit cost for the same service, we may suspect that the hospital with the lower unit cost performs better than the other one. To validate the previous hypothesis, one would have to break down the difference in order to understand why those differences exist, evaluating at the same time the practices followed within each hospital. To clarify the previous argument, we can use an example. Using data from Hospital 1 and 2, we observed that the unit cost computed for medical consultation corresponds to $\$ 11,534$ for Hospital 1 and to $\$ 12,268$ for Hospital 2 (See Table 6). When analyzing why these difference exists, we can see that there are three activities that account for at least four-fifths of the indirect cost of the ED for both hospitals. Out of these three activities, two of them (Medical evaluation and Medical re-evaluation) consume a larger proportion of indirect costs in Hospital 1 than Hospital 2 , mainly due to a larger volume of medical consultations in Hospital 1 compared to Hospital 2. For the remaining activity (Record indications to the patient), the leading cause for the discrepancy between the two hospitals is the shorter amount of time that takes to perform this activity in Hospital 1. After comparing the practices between the two hospitals, we concluded that the use of information systems to carry out the activity accounts for the minutes saved.
Governments should encourage these types of methodologies in order to promote transparency, efficiency, and cost control through a better calculation of ED charges.

Future research could use this cost objects list to assess whether the systematic comparison of income and costs within the emergency unit, as well as between different EDs, would allow us to detect opportunities for improvement indicating which processes should be intervened.

\section{Conclusions}

Cost objects have financial importance because they are the foundations of health insurance billing, and thus are tied to health systems financing. Different published studies use various types of cost objects for EDs. However, the lack of standardization and homogeneity in defining cost objects make comparing among units/ services difficult and sometimes even impossible.

This study provides EDs with a standardized methodology to identify a list of cost objects that facilitates their management and a methodology to adapt this list to their own context. This list is better than the proposals to date and can be applied to any hospital. Hospitals may have all these cost objects or just a subset of them depending on the services they provide. Moreover, the

Table 5 Example of costing at a diagnosis level (Chilean Pesos $=$ CLP)

\begin{tabular}{ll}
\hline Cost Objects & ICD-10 Code \\
\hline Medical consultation & J13: Pneumonia due to Streptococcus pneumoniae \\
Arterial blood gas sample & $\$ 11,710$ \\
Blood sampling & $\$ 3876$ \\
Management of imaging tests & $\$ 5795$ \\
Intramuscular prescribed drugs administration & $\$ 5689$ \\
Administration of non-injectable prescribed drugs & $\$ 6724$ \\
Nebulization & $\$ 5714$ \\
Total Cost & $\$ 4202$ \\
\hline
\end{tabular}


Table 6 Cost Comparison between Hospital 1 and 2 for the Medical Consultation Cost Object (Chilean Pesos = CLP)

\begin{tabular}{|c|c|c|c|c|c|}
\hline \multirow[t]{2}{*}{ Activity } & \multirow[b]{2}{*}{ Cost Driver } & \multicolumn{2}{|l|}{ HOSPITAL 1} & \multicolumn{2}{|l|}{ HOSPITAL 2} \\
\hline & & Annual Cost (CLP) & $\%$ & Annual Cost (CLP) & $\%$ \\
\hline Request of medical advice from physician & Time & $\$ 8.457 .972$ & $2,0 \%$ & $\$ 7.249 .918$ & $1,7 \%$ \\
\hline Medical evaluation & Time & $\$ 146.054 .786$ & $34,4 \%$ & $\$ 111.668 .897$ & $26,3 \%$ \\
\hline Medical re-evaluation & Time & $\$ 152.047 .070$ & $35,8 \%$ & \$116.224.158 & $27,4 \%$ \\
\hline Take vital signs & Time & $\$ 29.179 .405$ & $6,9 \%$ & $\$ 25.041 .997$ & $5,9 \%$ \\
\hline Call patient into the examing area & Number of patients & $\$ 28.583 .417$ & $6,7 \%$ & $\$ 24.356 .080$ & $5,7 \%$ \\
\hline Record indications to the patient & Number of patients & $\$ 88.170 .350$ & $20,8 \%$ & $\$ 109.191 .496$ & $25,7 \%$ \\
\hline Monitoring of clean laundry stock & Number of patients & $\$ 3.646 .956$ & $0,9 \%$ & $\$ 3.574 .159$ & $0,8 \%$ \\
\hline Coordinate personnel & Time & $\$ 7.402 .449$ & $1,7 \%$ & $\$ 6.309 .599$ & $1,5 \%$ \\
\hline Cleaning of the ED & Number of patients & $\$ 3.114 .947$ & $0,7 \%$ & $\$ 2.989 .540$ & $0,7 \%$ \\
\hline Securty survaillance & Number of patients & $\$ 5.698 .803$ & $1,3 \%$ & $\$ 5.044 .004$ & $1,2 \%$ \\
\hline \multirow[t]{4}{*}{ Management of the unit } & Number of patients & $\$ 15.089 .370$ & $3,6 \%$ & $\$ 13.171 .222$ & $3,1 \%$ \\
\hline & Total Cost & $\$ 487.445 .524$ & & $\$ 424.821 .069$ & \\
\hline & Number of medical consultations & 42.262 & & 34.628 & \\
\hline & Unit cost & $\$ 11.534$ & & $\$ 12.268$ & \\
\hline
\end{tabular}

final list may end up with new cost objects based on differences in practices across countries. This list allows to trace processes, compute costs and comparability among other EDs, provides an economic sense in its grouping, and it is flexible with any costing methodology and classification system.

\section{Abbreviations \\ EDs: Emergency Departments.; DRGs: Diagnostic Related Groups; ICD: International Classification of Diseases; ABC: Activity-Based Costing; TDABC: Time-Driven Activity-Based Costing; UML: Unified Modeling Language}

\section{Acknowledgments}

The authors thank the hospitals who participated on this research.

\section{Authors' contributions}

The contribution of the author was as followed: VF developed the original research idea and questions, obtained the data for this study, conducted data analysis, interpreted the results, and wrote the manuscript. LN contributed to the original research idea and questions, interpreted the results, and contributed to the writing and revisions of the manuscript. AN conducted data analysis, interpreted the results, and wrote the manuscript. RM contributed to the writing and revisions of the manuscript. All authors read and approved the final manuscript.

\section{Funding}

Project FONDEF IT13/10003.

The funders had no role in study design, data collection and analysis, decision to publish, or preparation of the manuscript.

\section{Availability of data and materials}

The datasets used and/or analysed during the current study are available from the corresponding author on reasonable request.

\section{Ethics approval and consent to participate}

This article does not require ethics approval. There is not human involvement in this study. Consent from the patient is not required, this study reports an assessment of the hospital situation not at the patient level. A consent form was written and signed to participate in the project by the hospital director.
Consent for publication

Not applicable.

\section{Competing interests}

The authors declare no competing interests.

\section{Author details}

${ }^{1}$ School of affiliation: Department of Management Control and Information Systems, School of Economics and Business, Universidad de Chile, Zip code: 8330015, Diagonal Paraguay 257, office, 2004 Santiago, Chile. ${ }^{2}$ School of affiliation: Business Department, University of Navarra, Pamplona, Navarra, Spain.

Received: 27 June 2019 Accepted: 1 June 2020

Published online: 17 June 2020

\section{References}

1. Lee MH, Schuur JD, Zink BJ. Owning the Cost of Emergency Medicine: Beyond 2\%. Ann Emerg Med. 2013;62(5):498-505.e3.

2. Horngren CT, Datar SM, Rajan MV. Cost accounting: a managerial emphasis. 14th ed. Upper Saddle River: Pearson/Prentice Hall; 2012. 869 p.

3. Baker JJ. Activity-based costing and activity-based management for health care. Gaithersburg: Aspen Publishers Inc., U.S; 1998. p. 385.

4. Ross TK. Analyzing health care operations using ABC. J Health Care Finance. 2004;30(3):1-20

5. Popesko B, Novák P. Application of ABC method in hospital management. En Greece: WSEAS Press; 2011

6. Cameron J, Baraff L, Sekhon R. Case-mix classification for emergency departments. Med Care. 1990;28(2):146-58.

7. Rajabi A, Dabiri A. Applying activity based costing (ABC) method to calculate cost Price in hospital and remedy services. Iran J Public Health. 2012:41(4):100-7.

8. Alvarado-Jaramillo J, Gonzáles-Ramos A, Mendoza-Arana P. Análisis de costos en dos unidades de cuidados intensivos pediátricos del Ministerio de Salud del Perú. An Fac Med. 2011;72(4):249-54.

9. Tejedor M, Jiménez L, Bandera J, Grupo de Costes de la SEMES. El coste de los procesos clínicos en los servicios de urgencias y emergencias. Emergencias. 1998;10(6):335-405.

10. Holmes RL, Schroeder RE. ABC estimation of unit costs for emergency department services. J Ambul Care Manage. 1996;19(2):22-30. https://doi. org/10.1097/00004479-199604000-00005. 
11. Garg N, Gupta S, Lathwal A, Garg R. A study of cost incurred in providing emergency care services in an apex tertiary care hospital. Int J Res Found Hosp Healthc Adm. 2016;4(1):45-50.

12. Cao P, Toyabe S-I, Akazawa K. Development of a practical costing method for hospitals. Tohoku J Exp Med. 2006;208(3):213-24.

13. Yen-Ju Lin B, Chao T-H, Yao Y, Tu S-M, Wu C-C, Chern J-Y, et al. How can activity-based costing methodology be performed as a powerful tool to calculate costs and secure appropriate patient care? J Med Syst. 2007;31(2): 85-90.

14. Udpa S. Activity cost analysis: a tool to cost medical services and improve quality of care. Manag Care Q. 2001;9(3):34-41.

15. Javid M, Hadian M, Ghaderi H, Ghaffari S, Salehi M. Application of the activity-based costing method for unit-cost calculation in a hospital. Glob J Health Sci. 2016;8(1):165-72.

16. Yun BJ, Prabhakar AM, Warsh J, Kaplan R, Brennan J, Dempsey KE, et al. Time-driven activity-based costing in emergency medicine. Ann Emerg Med. 2016;67(6):765-72.

17. Núñez A, Chi C. Equity in health care utilization in Chile. Int J Equity Health. 2013;12:58.

18. Kaplan R, Cooper R. Cost and effect: using integrated cost systems to drive profitability and performance. Boston: Business School Press; 1998.

19. Bertoni M, Lutilsky I. Opportunities for the improvement of cost accounting systems in public hospitals in Italy and Croatia: A Case Study. J Contemp Manag Issues. 2017:22(Special Issue):109-28.

\section{Publisher's Note}

Springer Nature remains neutral with regard to jurisdictional claims in published maps and institutional affiliations.

Ready to submit your research? Choose BMC and benefit from:

- fast, convenient online submission

- thorough peer review by experienced researchers in your field

- rapid publication on acceptance

- support for research data, including large and complex data types

- gold Open Access which fosters wider collaboration and increased citations

- maximum visibility for your research: over $100 \mathrm{M}$ website views per year

At BMC, research is always in progress.

Learn more biomedcentral.com/submissions 